\title{
CORRELAÇÃO DA INFILTRAÇÃO DAS CÉLULAS NATURAL KILLER (NK) CD 57+ NO PROGNÓSTICO DO ADENOCARCINOMA GASTRICO
}

\author{
Gástrico correlation of natural killer cell with the prognosis of gastric adenocarcinoma \\ Déborah ROSSO, Moacyr P. RIGUEIRO, Paulo KASSAB, Elias Jirjoss ILIAS, \\ Osvaldo A. P. CASTRO, Neil Ferreira NOVO, Laércio G. LOURENÇO
}

Trabalho realizado na Faculdade de Medicina de Santo Amaro - FMUNISA e Escola Paulista de Medicina - UNIFESP, São Paulo, SP, Brazil.
DESCRITORES - Adenocarcinoma. Neoplasias gástricas. Células Natural Killer. Sobrevida.
RESUMO - Objetivo - Avaliar a concentração da célula Natural Killer (NK) no adenocarcinoma gástrico operado, e sua correlação com fatores prognósticos e sobrevida Métodos - Foram estudados 72 doentes portadores de adenocarcinoma gástrico e que foram submetidos à gastrectomia com linfadenectomia D2. A concentração de célula NK foi avaliada por técnica de imunoistoquímica pelo reagente CD57. Os doentes foram divididos em dois grupos: alta concentração de células $(n=32)$ ( $>15$ células $/ 10$ campos de grande aumento) e baixa concentração ( $\leq 15$ células/10 campos de grande aumento). Esses dois grupos foram comparados com seguintes fatores prognósticos: gênero, idade, localização do tumor, grau de diferenciação celular, classificação de Lauren, estádio, disseminação linfática, metástases e sobrevida. A curva de Kaplan-Meier foi empregada para avaliação de sobrevida e a análise multivariada para avaliação dos fatores prognósticos. Resultados - Não houve relação das células NK com as diversas variáveis estudadas, a não ser com o estádio, onde houve significância $(p<0,02)$, quando houve alta concentração nos estádios mais avançados. A sobrevida foi maior $(p=0,0025)$ no grupo de Alta concentração de NK. Na análise de sobrevida no estádio tardio, o grupo de alta concentração obteve sobrevivência maior $(p<0.0001)$. E na análise multivariada a concentração de células NK foi um fator prognóstico independente $(p=0,0027$, hazard ratio $=0.343)$. Conclusões $-A$ concentração de células NK não difere entre as variáveis prognósticas, com exceção do estadiamento. Doentes com alta concentração de células NK apresentaram maior sobrevida quando comparados aos de baixa concentração, principalmente no estádio tardio.

\section{Correspondência:}

Débora Rosso,

e-mail: deborahderosso@uol.com.br

Fonte de financiamento: não há

Conflito de interesses: não há

Recebido para publicação:

Aceito para publicação:

HEADINGS - Adenocarcinoma. Stomach neoplasms. Natural Killer Cells. Survival.
ABSTRACT - Background - To evaluate the concentration of Natural Killer cells (NK) cells in adenocarcinoma of the stomach, and its correlation with prognostic factors and survival. Methods - Seventy-two patients with gastric adenocarcinoma who underwent gastric resection surgery and D2 lymphadenectomy in the period 1997-2007 were analyzed. The concentration of NK cells was evaluated by immunohistochemistry technique with the reagent CD57. Patients were divided into two groups: high concentration $(n=32)$ (more than 15 cells per 10 high power field) and low concentration (less or equal than 15 cells per 10 high power field). These two groups were compared with several prognostic factors such as: gender, age, tumor location, tumor differentiation, Lauren classification, stage, lymph nodes involvement, distant metastases and survival. The Kaplan-Meier curve was applied to evaluate survival and multivariate analysis of prognostic factors for evaluation. Results - There was no relationship of NK cells with the several variables studied, except to the tumor stage $(p<0.02)$ with high concentration in more advanced stages. Survival was better $(p=0.0025)$ in the group of high concentration of NK. The survival analysis in advanced stage shown that the group with high concentration had higher survival $(p<0.0001)$. In multivariate analysis, the concentration of NK cells was an independent prognostic factor $(p=0.0027$, Hazard Ratio $=0343$ ). Conclusions - The concentration of NK cells did not differ among the prognostic variables, with the exception of the staging. Patients with high concentration of NK cells showed a higher survival rate when compared to the low concentration, especially in the advanced stage. 


\section{INTRODUÇÃO}

$\mathrm{O}$ câncer gástrico representa a terceira neoplasia mais frequente no mundo. Com taxas de mortalidade de até $70 \%$ nos países ocidentais. É a segunda causa de óbito por câncer no mundo (INCA 2010).

O seu prognóstico está diretamente ligado ao estádio evolutivo, sendo pior, obviamente, nas fases mais avançadas. A infiltração tumoral na parede gástrica, o comprometimento peritoneal, ressecção tumoral incompleta, a propagação linfática regional, o tamanho do tumor e o grau de diferenciação histológica constituem fatores relacionados com o prognóstico e são aceitos, universalmente, como estadiamento cirúrgico. Destacam-se ainda alterações histopatológicas e de biologia molecular como fatores de prognóstico.

O sistema imune está cada vez mais sendo estudado nos doentes portadores de neoplasias, assim como o infiltrado inflamatório peri-tumoral.

As células Natural Killer (NK), foram descritas em 1969 como linfócitos alógenos matadores de células tumorais in vitro, e em 1973 estes linfócitos foram denominados de células NK, sendo consideras as células capazes de realizar a vigilância imunológica contra tumores ${ }^{15}$

As NK funcionam como um componente da imunidade inata e serve como a primeira linha de defesa contra neoplasias e células infectadas por vírus. Em alguns estudos foi possível demonstrar que as células NK têm atividade citotóxica espontânea contra células tumorais, podendo afetar o prognóstico de tumores intestinais $4,7,10,13,14,17,19$. As células NK constituem pequena porcentagem do infiltrado linfocitário ao redor do tumor, mas elas podem ser o suficiente para ter um efeito antitumoral local. Vários marcadores têm sido analisados para saber se há significância como fatores prognósticos ${ }^{6,168}$, mas a importância clinica da infiltração tumoral das células NK ainda não está clara nos vários tipos de carcinoma ${ }^{3}$.

O objetivo deste estudo foi correlacionar a densidade de células NK no adenocarcinoma gástrico com os diversos fatores prognósticos e com a sobrevida.

\section{MÉTODOS}

No período de 1997 a 2007, 72 pacientes portadores de adenocarcinoma gástrico foram submetidos à gastrectomia com linfadenectomia D2 com intenção curativa (R0), no Departamento de Cirurgia da FMUNISA.

Os fatores de inclusão foram: tecidos e doentes submetidos à ressecção gástrica total ou parcial com linfadenectomia à D2 com intenção curativa; terem diagnóstico de adenocarcinoma confirmados por exame anatomopatológico; ausência de tratamentos quimioterápicos e/ou radioterápico neoadjuvante ou adjuvante.

Os fatores de exclusão foram: a não confirmação de tumor tipo adenocarcinoma na amostra; má conservação dos blocos, não sendo possível realizar o estudo imunoistoquímico; doentes que foram submetidos à cirurgia paliativa; perda de seguimento do paciente. Foi considerado critério de exclusão somente para análise da sobrevida, os doentes que morreram no pós-operatório imediato (até 30 dias).

A coloração pela Hematoxilina-Eosina (HE) foi utilizada para confirmação de presença de adenocarcinoma, classificação do tipo histológico e de Laurén e o estadiamento TNM.

O estudo imunoistoquímico foi realizado para o anticorpo CD57, de células NK, avaliados em cortes histológicos de $4 \mu \mathrm{m}$ de espessura em lâminas previamente silanizadas, deixadas na estufa a $60^{\circ} \mathrm{C}$ por 24 horas, incubação com anticorpo primário $\mathrm{CD}^{2} 7\left(\mathrm{DAKO}^{\circledR}{ }^{\circledR} \mathrm{m} 7271\right.$ lote 00029028) nas diluições de 1: 150 e 1: 50, respectivamente, em BSA ${ }^{\circledR}$ (soro albumina bovina a $1 \%$ ), durante a noite, a $4^{\circ} \mathrm{C}$ em câmara úmida; lavagem em solução de $\mathrm{PBS}^{\circledR}$; incubação em anticorpo secundário, biotinilado (LSAB-plus ${ }^{\circledR}$ ) do "kit" LSAB /HRP Duet Mouse / Rabbit, Dako ${ }^{\circledR}$ /código K0690, por 20 minutos a $37^{\circ} \mathrm{C}$; lavagem em solução de $\mathrm{PBS}^{\circledR}{ }^{\circledR}$; incubação com o complexo estreptoavidina-biotina-peroxidase $\left(\mathrm{DAKO}^{\circledR}\right)$ por 20 minutos a $37^{\circ} \mathrm{C}$; revelação da reação utilizando-se substrato cromógeno. Procederam-se, a seguir, a contra-coloração com Hematoxilina de Harrys por um minuto; depois, a imersão das lâminas em água amoniacal e lavagem em água corrente e destilada. Posteriormente fez-se a desidratação em concentrações crescentes de álcool etílico a 70, 80, 95 e $100 \%$.

Foram contadas todas as células em 10 campos de grande aumento (400x). A densidade de células NK foram classificadas em dois grupos: doentes com baixa concentração ( $\leq 15$ células /10CGA) e doentes com alta concentração (> 15 células /10CGA). Este ponto de corte foi utilizado segundo os estudos de Saito ${ }^{14}$ e Takashi ${ }^{17}$.

O teste de $\mathrm{X} 2$ foi usado para avaliação dos fatores clinicopatológicos. A sobrevivência foi analisada pela curva de Kaplan-Meier. $p<0.05$ foi considerado estatisticamente significante. A análise multivariada foi realizada pelo teste de regressão múltipla de Cox.

\section{RESULTADOS}

Dos 72 pacientes, 46 (63,9\% eram homens e 26 $(36,1 \%)$ mulheres. A média de idade foi de 57,32 anos variando de 31-84 anos com desvio-padrão de 1,27 para homens e 1,29 para mulheres. Nenhum doente recebeu tratamento adjuvante ou neo-adjuvante. Os pacientes que morreram no pós-operatório imediato foram excluídos da análise de sobrevivência. O seguimento dos doentes foi de no mínimo dois anos e no máximo de cinco.

O estudo demonstrou maior prevalência dos tumores mais avançados, sendo que o estádio IV foi de 23,6\% (Tabela 1).

A infiltração de células NK foi identificada no infiltrado do parênquima tumoral, (Figura 1). As células NK, no total dos doentes foram divididas em dois grupos: um de alta 
TABELA 1 - Distribuição dos 72 doentes submetidos à operação conforme o estadiamento clínico (JSGC)

\begin{tabular}{|c|c|}
\hline Estadiamento & $\mathrm{N}(\%)$ \\
\hline Ia & $5(6,9)$ \\
Ib & $15(20,8)$ \\
II & $9(12,5)$ \\
IIIa & $13(18,1)$ \\
IIIb & $13(18,1)$ \\
IV & $17(23,6)$ \\
\hline
\end{tabular}

concentração de células $(n=32)$ e outro de baixa $(n=40)$. Não houve diferença estatística nas seguintes variáveis analisadas: idade, gênero, localização, profundidade (T), invasão linfática $(\mathrm{N})$ e diferenciação celular em relação à concentração de células NK. Quanto ao estádio houve significância $(p<0,02 \%)$ quando relacionados à alta concentração com estádios mais avançados (Tabela 2).

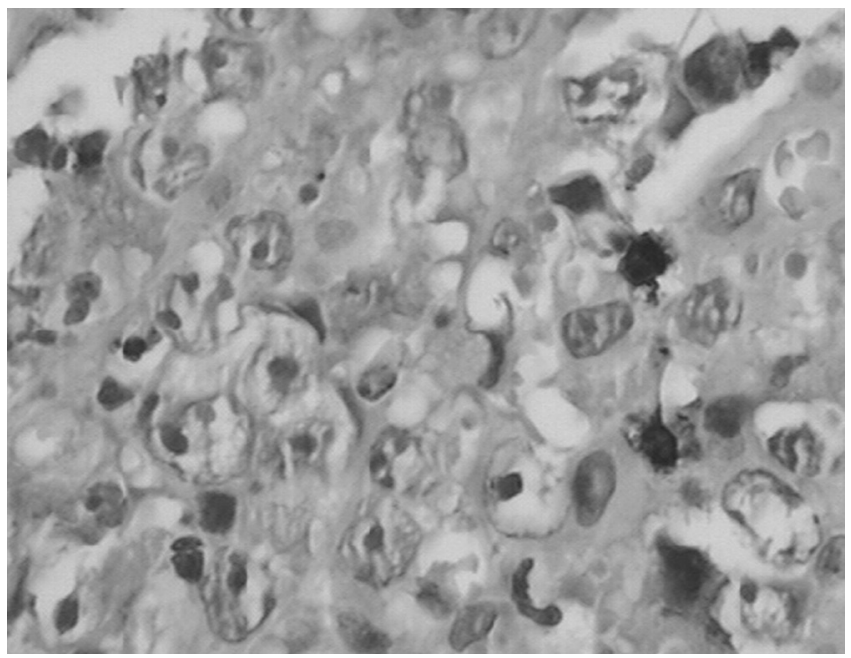

FIGURA 1 - Célula Natural Killer no adenocarcinoma gástrico (imunoistoquímica CD57-400x)

TABELA 2 - Estádios inicial e tardio e sua relação com a concentração de células NK nos doentes operados

\begin{tabular}{ccccccccc}
\hline & \multicolumn{2}{c}{ Alto } & \multicolumn{2}{c}{ Baixo } & \multicolumn{2}{c}{ Total } & \multirow{2}{*}{$\%$ Alto } \\
\cline { 1 - 7 } & $\mathbf{N}$ & $\%$ & $\mathbf{N}$ & $\%$ & $\mathbf{N}$ & $\%$ & \\
\hline Inicial & 8 & 24,2 & 21 & 53,8 & 29 & 40,3 & 27,6 \\
\hline Tardio & 25 & 75,8 & 18 & 46,2 & 43 & 59,7 & 58,1 \\
\hline Total & 33 & 100 & 39 & 100 & 72 & 100 & 45,8 \\
\hline
\end{tabular}

Em relação à sobrevida houve diferença significante no grupo de alta concentração $(p=0.0025)$ (Figura 2) que se pronunciou mais quando foi analisada a sobrevivência separadamente do grupo mais avançado, aqui denominado de tardio, onde obtevese significância de $p<0.0001$ (Figura 3). E na análise multivariada observou-se risco de morte $66 \%$ menor no grupo de alta concentração em relação ao grupo de baixa concentração ( $\mathrm{HR}=0.343$ e $\mathrm{p}=0.0027) \mathrm{em}$ modelo ajustado por sexo e idade (Tabela 3 ).

Ao nível de significância de $5 \%$, os doentes com alta concentração tiveram risco de mortalidade significativamente menor $(\mathrm{HR}=0.343 ; \mathrm{CI}=95 \%$ 0.1710690, $p=0.0027)$.

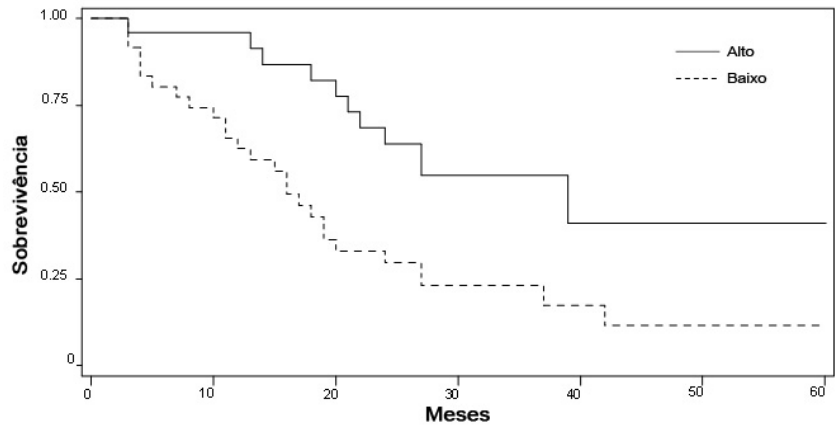

NOTA: Em nível de significância de 5\%, observou-se diferença significativa entre as duascurvas de sobrevida (Log-rank test $p=0.0025$ )

FIGURA 2 - Curva de sobrevida conforme a concentração alta versus baixa de células NK nos doentes submetidos à gastrectomia com linfadenectomia D2

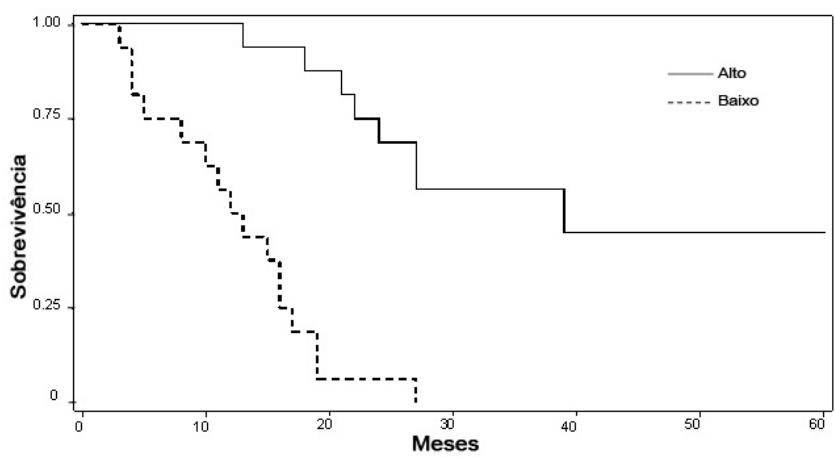

NOTA: Em nível de significância de 5\%, observou-se diferença significativa entre as duas curvas de sobrevida. (Log-rank test $p<0.0001)$

FIGURA 3 - Curva de sobrevida de Kaplan-Meier comparando a concentração de células NK no estádio tardio nos doentes submetidos à operação

TABELA 3 - Análise multivariada de Cox, em modelo ajustado por sexo e idade, comparando a mortalidade de Alta concentração de células NK versus Baixa concentração nos doentes operados por adenocarcinoma gástrico

\begin{tabular}{cccccccccc|}
\hline Variável & DF & $\begin{array}{c}\text { Parâmetro } \\
\text { Estimado }\end{array}$ & $\begin{array}{c}\text { Desvio- } \\
\text { Padrão }\end{array}$ & X2 & Pr $>$ X2 & $\begin{array}{c}\text { Hazard } \\
\text { Ratio }\end{array}$ & \multicolumn{2}{c|}{$95 \%$ CI } \\
\hline Idade & 1 & 0.00273 & 0.01327 & 0.0425 & 0.8368 & 1.003 & 0.977 & 1.029 \\
Feminino & 1 & -0.38638 & 0.34682 & 1.2412 & 0.2652 & 0.680 & 0.344 & 1.341 \\
\hline Alto & 1 & -1.06946 & 0.35658 & 8.9954 & 0.0027 & 0.343 & 0.171 & 0.690 \\
\hline
\end{tabular}

\section{DISCUSSÃO}

Há muitos estudos detalhando a correlação entre prognóstico, estádio da doença, alterações histológicas e reação imune local e sistêmica em pacientes com câncer gástrico 2,4,9,10,11,13,12,20.

A respeito das células NK, dos 72 casos analisados, $40(55,6 \%)$ apresentaram baixa densidade de células e $32(44,4 \%)$ alta, que se distribuíram uniformemente entre os gêneros feminino (42,3\%) e masculino (45,6\%). Esses resultados assemelham-se aos encontrados por Canöz ${ }^{1}$, Hyakudomi ${ }^{5}$ e Ishigami ${ }^{7}$. Com isso, considera- 
se que fatores hormonais não devem influenciar na concentração de células NK.

Ishigami $^{7}$ observou que não houve diferença estatística quanto à localização anatômica e a distribuição de alta ou baixa densidade de células NK, o mesmo achado que este estudo demonstrou, o que leva a crer que a localização do tumor não influencia a resposta imunológica. Com relação à profundidade da lesão (T), o referido autor demonstrou $p<0,05$ nos tumores classificados como T2, o que não ocorreu nesta análise

O estadiamento desta amostra analisado pela Japanese Society Gastric Cancer e correlacionado com a alta ou baixa densidade de células, observou tendência de associação de alta densidade com os tipos mais avançados. Então, realizouse associação e classificou-se como inicial ( $\mathrm{Ia}, \mathrm{Ib}, \mathrm{II})$ e tardio (IIIa, IIIb e IV) e obtive-se diferença estatística ( $p<0,02)$, o que confirma os primeiros estudos sobre processo inflamatório peri-tumoral, como o de Davessar ${ }^{4}$ demonstrando melhor prognóstico, conforme maior processo inflamatório, independente do tipo de tumor ou do seu estadiamento. Isto leva a crer que o hospedeiro poderia se "defender" do câncer dependendo de sua resposta imunológica, englobando o tumor e impedindo que ele se disseminasse no organismo, apesar de poder aumentar localmente. Muito tempo se passou e ainda tenta-se entender o processo inflamatório peri-tumoral, só que agora, com conceitos mais modernos de imunologia tumoral.

Em trabalho publicado em 2007, Talmadge, Donkor e Scholar ${ }^{18}$, foi realizada uma revisão sobre todo o mecanismo de imunossupressão e imunorregulação, demonstrando a importância destes eventos não só para compreender a interação dos tumores com o sistema imune, como também para intervenções clínicas, como vacinas e imunoterapias.

A concentração da célula NK não mostrou diferença estatística nos diversos fatores prognósticos, com exceção do estadiamento, onde obtive-se correlação de alta concentração com estádios mais avançados (tardio), diferentemente de Ishigami ${ }^{8}$ que constatou predominância de alta concentração de células NK nos tumores de estádios iniciais.

Em relação à sobrevida, obtive-se resultado de melhor sobrevivência nos pacientes com alta concentração de células NK ( $p=0.0025)$, como Ishigami ${ }^{7,8}$, Canoz ${ }^{1}$ e Hyakudomi ${ }^{5}$. E um fato que chamou atenção revelando que esta diferença estatística fica mais evidente no estádio tardio $(p<0,0001)$, o que não ocorre no inicial. Isto mostra como é difícil entender o mecanismo de imunossupressão e imunorregulação tumoral.

Quando realizou-se análise multivariada comparando a mortalidade na alta concentração versus baixa em modelo ajustado por sexo e idade, obtive-se um risco de morte significantemente menor ( $H R=0,343 ; p=0.0027)$.

\section{CONCLUSÃO}

A concentração de células NK não difere entre as variáveis prognósticas com exceção do estadiamento, onde nota-se predomínio de alta concentração nos estádios mais avançados. Doentes com alta concentração de células NK apresentaram maior sobrevida do que os doentes com baixa concentração. A alta concentração de células NK pode ser considerada um fator prognóstico independente nos doentes com adenocarcinoma gástrico.

\section{REFERÊNCIAS}

1. Canöz O, Belenli O, Patiroglu TE. General features of gastric carcinomas and comparison of HSP70 and NK cell immunoreactivity with prognostic factors. Pathol Oncol Res. 2002;8:262-9.

2. Cimerman M, Repse S, Jelenc F, Omejc M, Bitenc M, Lamovec J. Comparison of Lauren's, Ming's and WHO histological classifications of gastric cancer as a prognostic factor for operated patients. Int Surg. 1994;79:27-32.

3. Coca S, Perez-Piqueras J, Martinez D, Colmenarejo A, Saez MA, Vallejo C, ET al. The prognostic significance of intratumoral natural killer cells in patients with colorectal carcinoma. Cancer. 1997;79:2320-8.

4. Davessar K, Pezzullo JC, Kessimian N, Hale JH, Jauregui HO. Gastric adenocarcinoma: prognostic significance of several pathologic parameters and histologic classifications. Hum Pathol. 1990;21:325-32.

5. Hyakudomi M, Matsubara T, Hyakudomi R, Yamamoto T, Kinugasa S, Yamanoi $A$, et al. Increased expression of fractalkine is correlated with a better prognosis and an increased number of both CD8+ T cells and natural killer cells in gastric adenocarcinoma. Ann Surg Oncol. 2008;15:1775-82.

6. Ishigami S, Aikou T, Natsugoe S, Hokita S, Iwashige H, Tokushige M, Sonoda S. Prognostic value of HLA-DR expression and dendritic cell infiltration in gastric cancer. Oncology. 1998;55:65-9.

7. Ishigami S, Natsugoe S, Hokita S, Xiangming C, Aridome K, Iwashige $H$, et al. Intranodal antitumor immunocyte infiltration in node-negative gastric cancers. Clin Cancer Res. 2000;6:2611

8. Ishigami S, Natsugoe S, Tokuda K, Nakajo A, Xiangming C, Iwashige H, et al. Clinical impact of intratumoral natural killer cell and dendritic cell infiltration in gastric cancer. Cancer Lett. 2000;159:103-8.

9. Kakeji Y, Maehara Y, Korenaga D, Tsujitani S, Haraguchi M, Watanabe A, et al. Prognostic significance of tumor-host interaction in clinical gastric cancer: relationship between DNA ploidy and dendritic cell infiltration. J Surg Oncol. 1993:52:207-12.

10. Lima OAT, Ribas-Filho JM, Czeczko NG, Malafaia O, Aoki SMS, Dietz UA, Araújo URMF, Ribas FM. Expressão citofotométrica do marcador CD34 no carcinoma epidermóide de esôfago. ABCD Arq Bras Cir Dig 2007;20(4):254-60

11. Lourenço LG. Relação entre a contagem da microdensidade vasal tumoral e o prognóstico do adenocarcinoma gástrico operado. [Tese] São Paulo: UNIFESP- Escola Paulista de Medicina; 1989.

12. Mader AMAA. Estudo clinico-patológico, da angiogênese, proliferação celular e da apoptose no adenocarcinoma gástrico de cárdia. [Doutorado] São Paulo: UNIFESP-EPM; 2005.

13. Nassif $A E$, Támbara-Filho R. Immunohistochemistry expression of tumor markers CD34 and P27 as a prognostic factor of clinically localized prostate adenocarcinoma.Rev. Col. Bras. Cir. 2010; 37(5): 338-344

14. Saito H, Tsujitani S, Ikeguchi M, Maeta M, Kaibara N. Relationship between the expression of vascular endothelial growth factor and the density of dendritic cells in gastric adenocarcinoma tissue. Br J Cancer. 1998;78:1573-7.

15. Sinkovics JG, Horvath JC. Human natural killer cells : a comprehensive review. Int. J. ONcol 2005;27(1):5-47

16. Songun I, van de Velde CJ, Hermans J, Pals ST, Verspaget HW, Vis AN, et al. Expression of oncoproteins and the amount of eosinophilic and lymphocytic infiltrates can be used as prognostic factors in gastric cancer. Dutch Gastric Cancer Group (DGCG). Br J Cancer. 1996;74:1783-8.

17. Takahashi A, Kono K, Itakura J, Amemiya H, Feng Tang $\mathrm{R}$, et al. Correlation of vascular endothelial growth factor- $C$ expression with tumor-infiltrating dendritic cells in gastric cancer. Oncology. 2002;62:121-7.

18. Talmadge JE, Donkor M, Scholar E. - Inflammatory cell infiltration of tumors: Jekill or Hyde. Cancer Metastasis Rev (2007) 26:373-400

19. Wu Y, Wang L, Zhang Y. Dendritic cells as vectors for immunotherapy of tumor and its application for gastric cancer therapy. Cell Mol Immunol. 2004;1:351-6.

20. Yamaguchi K, Saito H, Oro S, Tatebe S, Ikeguchi M, Tsujitani S. Expression of inducible nitric oxide synthase is significantly correlated with expression of vascular endothelial growth factor and dendritic cell infiltration in patients with advanced gastric carcinoma. Oncology. 2005;68:471-8. 